\title{
The Female Weight-Control Smoker: A Profile
}

\author{
Cynthia S. Pomerleau \\ Emily Ehrlich \\ James C. Tate \\ Judith L. Marks \\ Karen A. Flessland \\ Ovide F. Pomerleau
}

University of Michigan School of Medicine

\begin{abstract}
Hypothesizing the existence of a subgroup of female smokers for whom nicotine masks, and abstinence unmasks, a tendency toward hyperphagia and perhaps even subthreshold disordered eating, we compared female "weight-control smokers" (WC; $n=46$ ) and "non-weight-control smokers" (NWC; $n=52$ ) on smoking- and eating-related variables. We also examined the relationship between weight-control smoking and withdrawal symptomatology during 48-hours of nicotine abstinence ( $n$ $=23$ ) . Although WC were not more depressed, anxious, or nicotine-dependent than NWC, they were significantly more likely to report weight gain and increased hunger during abstinence; they also scored higher on Cognitive Restraint and Disinhibition (Three-Factor Eating Questionnaire). The expected correlation of cotinine with weight emerged for NWC but not for WC. Weight-control smoking correlated with increased eating during abstinence. Our findings suggest that WC use dietary restraint as well as smoking to manage weight, and that abstinence may precipitate episodes of disinhibited or binge eating. If WC overinclude women vulnerable to excess or unpredictable eating and consequently to substantial weight gain that can be managed by nicotine, highly focused treatment strategies may be helpful.
\end{abstract}

The peculiar and fascinating combination of pharmacological and sociocultural factors involved in weight-control smoking has generated considerable research over the past few years. Despite these efforts, however, attempts to determine the net impact of weight-control smoking on treatment efficacy, both in terms of attracting such smokers to treatment and achieving sustained abstinence, have produced a somewhat confusing picture. In the current climate of interest in treatment matching, a question no less appropriate than that of whether weightcontrol smoking is likely to deter cessation efforts or promote relapse is that of whether treatment success rates for people motivated to smoke by nicotine's anorectic properties can be improved upon; an answer to that question will

Preparation of this manuscript was supported by Grant CA 42730, awarded to Ovide F. Pomerleau by the National Cancer Institute.

Correspondence and requests for reprints should be sent to Cynthia S. Pomerleau, Behavioral Medicine Program, University of Michigan Department of Psychiatry, 475 Market Place, Suite L, Ann Arbor, MI 48108. 
depend on our ability to distinguish such smokers and delineate their characteristics in such a way as to suggest rational therapies for this population.

A number of studies, using various measures to define weight-control smoking, have shown that the phenomenon is relatively rare in male smokers $12 \%$ to $25 \%$ ) but that it accounts for up to $40 \%$ of female smokers (e.g., Camp, Klesges, \& Relyea, 1993; Weekley, Klesges, \& Relyea, 1992). The preponderance of women in this category is often attributed to sociocultural factors (French, Jeffery, Pirie, \& McBride, 1992; Schwartz, Thompson, \& Johnson, 1982). This explanation has face validity and is undoubtedly correct at least in part; after all, no rat would be likely to self-administer nicotine to maintain a svelte profile, nor would individuals living in a culture that valued plumpness (e.g., as a symbol of prosperity) be likely to respond to this property of nicotine.

There is also evidence, however, based on studies of postcessation changes in weight and eating behavior, that women are more sensitive to the effects of nicotine upon food intake and weight. Hall, McGee, Tunstall, Duffy, and Benowitz (1989) have demonstrated gender differences in postcessation eating that emerge by the end of the first week of abstinence and persist for at least 6 months following withdrawal. Women gain more weight than do men following smoking cessation and are also more likely than men to be "supergainers" ( $\geq 13$ kg; Williamson, Madans, Anda, Kleinman, Giovino, \& Byers, 1991). Thus, the excess of female weight-control smokers may not be simply a response to a greater concern with slimness but also to a greater likelihood that nicotine withdrawal will produce real-world consequences in terms of food intake and weight gain. Women have been shown to have higher expectations of nicotine's utility in controlling appetite and weight (Brandon \& Baker, 1991), and it appears that they are right.

These considerations led us to speculate that phrases like "smoking as a dieting strategy" (Weekley et al., 1992) might obscure individual differences not only in level of concern about weight gain but also in sensitivity to nicotine's effects on body weight. Although the mechanisms underlying these effects are probably multifactorial (Klesges \& Shumaker, 1992; Leischow \& Stitzer, 1991), there is considerable evidence to suggest that changes in eating behavior play at least some role in the process (Grunberg, 1982; IIall et al., 1989; Moffatt \& Owens, 1991). Our working hypothesis, therefore, was that a subgroup of smokers, primarily women, may be particularly likely to be "weight-control smokers" because nicotine masks, and nicotine abstinence unmasks, a tendency toward hyperphagia and perhaps even subthreshold disordered eating. As a preliminary attempt to examine this hypothesis, we used a questionnaire designed to identify a group of female "weight-control smokers" and a control group not motivated by weight management considerations and compared their responses on a variety of measures designed to assess eating behavior and the effects of nicotine withdrawal upon eating-related variables. Other variables that might provide an alternative explanation of the differences were included as well. We also examined experimentally, in a smaller group of female subjects, the relationship of weight-control smoking with the emergence of withdrawal symptomatology within 48 hours of nicotine abstinence. 


\section{METHOD}

\section{Subjects}

Subjects for the two studies were drawn from a larger sample of 181 female smokers recruited to the University of Michigan Behavioral Medicine Program to participate in either laboratory investigations $(n=108)$ or clinical trials of pharmacological agents to promote smoking cessation $(n=73)$.

\section{Assessment of Weight-Control Smoking}

The Weight-Control Scale (WCSS) consists of three statements formulated in an attempt to determine the extent to which individuals perceive smoking as a weight-control tool: (a) I smoke to keep from gaining weight. (b) Smoking helps me control my appetite. (c) I don't get so hungry when I smoke. Possible responses to each statement were 0 (Not at all), 1 (A little), 2 (Quite a bit), and 3 (Very much so); thus, total scores could range from 0 to 9 . The questions were embedded in a version of the Smoking Motivation Questionnaire (SMQ), modified to include only three items per "motive" (Russell, Peto, \& Patel, 1973; Tate, Pomerleau, \& Pomerleau, in press-a). In this sample of 390 subjects, the WCSS had a Cronbach's coefficient alpha of .86 .

\section{Study 1}

In order to develop a profile of the smoker who is particularly concerned with or susceptible to weight gain, a subsample of weight-control smokers (WC) and a control sample of non-weight-control smokers (NWC) were identified as follows. To be classified as WC, subjects were required to have a total WCSS score of $\geq 6$ (i.e., mean answer for each of the three items had to be at least 2, or Quite a bit). Subjects who scored 0 or 1 were classified as NWC. Forty-six of the 181 women (25.4\%) qualified as WC (mean WCSS score $\pm S D=7.4 \pm 1.2$ ) and $52(28.7 \%$ ) as NWC (mean WCSS score \pm SD $=.4 \pm .5$ ). Thus, each group constituted about a quarter of the entire sample. By contrast, of the 209 male smokers also included in the database (148 laboratory volunteers, 61 patients in smoking cessation trials), only $15(7.2 \%)$ were WC, whereas $96(45.9 \%)$ were classified as NWC, $\chi^{2}=28.21, d f=2, p<.0001$.

\section{Demographic Variables}

Demographic variables collected included age, height, weight, Body Mass Index $\left(\mathrm{BMI}=\mathrm{kg} / \mathrm{M}^{2}\right)$, race, and educational level, as well as whether subjects were patients in treatment for smoking cessation or paid volunteers.

\section{Smoking-Related Variables}

Two measures of degree of dependence were included: (a) the Fagerstrom Tolerance Questionnaire (FTQ; Fagerstrom, 1978) and (b) plasma cotinine levels as measured by gas chromatography (GC; Jacob, Wilson, \& Benowitz, 1981) or high-performance liquid chromatography (HPLC; Hariharan, VanNoord, \& 
Greden, 1988). Two validated "metamotives" were derived from the seven smoking motives of the modified SMQ: Pharmacological (Stimulation, Addictive, Automatic, and Sedation) and Nonpharmacological (Indulgent, Psychosocial, and Sensorimotor). Smoking has been shown to delay gastric emptying and perhaps to promote satiety (Gritz, Ippoliti, Jarvik, Rose, Shiffman, Harrison, \& Van Vunakis, 1988); because it seemed possible that WC might be more inclined to "use" cigarettes for this purpose, we queried whether the cigarette smoked at mealtime was the favorite cigarette. Responses to queries on (a) number of past quit attempts, (b) whether weight changes and appetite changes had been experienced during previous quit attempts (rated $1=$ decrease; $2=$ no change; and $3=$ increase), and (c) presence or absence of increases in anxiety, anger, depression, or tiredness, or decreases in concentration during previous quit attempts were evaluated.

\section{Eating, Alcohol, Caffeine, and Exercise}

The three subscales of the Three-Factor Eating Questionnaire were administered (TFEQ; Stunkard \& Messick, 1985): Cognitive Restraint, Disinhibition, and Hunger. Measures of (a) alcohol intake per week (in drinks/week: 1 drink = $6 \mathrm{oz}$ wine, $12 \mathrm{oz}$ beer or wine cooler, or $2 \mathrm{oz}$ liquor); (b) caffeine intake per day (calculated on a scale of $0-9:(0=n o n e ; 1=<50 \mathrm{mg} ; 2=50-100 \mathrm{mg} . .8=$ $351-400 \mathrm{mg} ; 9=>400 \mathrm{mg}$ ); and (c) amount of exercise per week in hours were also included.

\section{Trait Measures}

Anxiety was measured using the State-Trait Anxiety Inventory/trait (STAI/trait; Spielberger, Gorsuch, Lushene, Vagg, \& Jacobs, 1983). Because of protocol variations, baseline depression scores were collected via the Beck Depression Inventory (BDI; Beck, Ward, Mendelson, Mock, \& Erbaugh, 1961) in some subjects and via the Center for Epidemiological Studies Depression scale (CES-D; Weissman, Sholomakis, Pottenger, Prushoff, \& Locke, 1977). Subjects who took the BDI comprised $41 \%$ of the WC and $48 \%$ of the NWC; because of this similar distribution, we simply classified all subjects, regardless of group, who scored in the upper quartile of our sample for each scale (BDI $\geq 15$; CES-D $\geq 19$ ) as High-Depressed.

Data on most variables were available for most subjects; an exception was the TFEQ, for which ratings were only made by $12 \mathrm{WC}$ and $18 \mathrm{NWC}$, all of whom were paid volunteers in laboratory studies.

\section{Study 2}

A subsample of 23 female smokers who participated in a laboratory study, in which the consistency of withdrawal effects was tested (Tate, Pomerleau, \& Pomerleau, 1993), provided WCSS data as well as retrospective assessments (last 48 hours) of withdrawal symptomatology measured on bipolar visual analogue scales querying 9 DSM-III-R (American Psychiatric Association, 1987) withdrawal symptoms (craving, irritability, impatience, restlessness, excessive hunger, 
increased eating, decreased heart rate, difficulty concentrating, and anxiety). Assessments were made at the end of 24 and 48 hours, and the mean scores for each symptom were subtracted from the corresponding baseline (ad lib smoking) score. Correlation coefficients were computed to determine whether WCSS scores predicted severity of any withdrawal symptoms, particularly those associated with hunger and food intake.

\section{RESULTS}

\section{Study 1}

Results are shown in Table 1. There were no important significant differences between WC and NWC on any demographic measure, using chi-square or $t$ tests as appropriate. Though cotinine levels were marginally higher in the NWC than they were in the WC, WC scored significantly higher by multivariate analysis of variance (MANOVA) on the pharmacological "metamotive" than did NWC, with all but the "automatic" factor being significantly greater on the univariate analyses. Although WC had made fewer quit attempts than had NWC, differences did not reach significance. During previous periods of abstinence, WC were significantly more likely to report changes in appetite and weight, as well as to experience increased anxiety. WC scored significantly higher on the Cognitive Restraint and Disinhibition factors of the TFEQ. They took in marginally more caffeine per week. There were no significant differences between groups on either of the trait measures.

Plasma cotinine level was significantly correlated with weight in NWC $(r=-.43$, $n=25, p=.031)$ but not in WC $(r=-.11, n=28$, n.s. $)$.

\section{Study 2}

Only one withdrawal symptom, increased eating, was significantly correlated with WCSS score $(r=.43, p=.043)$; correlation of WSCC score with excessive hunger fell short of significance $(r=.32$, n.s.). (Correlations with remaining symptoms, including anxiety, were considerably lower.)

\section{DISCUSSION}

The ways in which the female WC and NWC did not differ were in some ways as interesting as the ways in which they did. They did not differ significantly on any demographic variables (except for a small adventitious difference in height). There was no evidence that WC were more depressed or anxious than their NWC counterparts. Patients in treatment and laboratory volunteers were evenly distributed between the WC and NWC groups. (An important caveat about these and all our other conclusions is that our sample consisted largely of white women, and so the conclusions might not apply to blacks, Hispanics, or Asians; see Camp, Klesges, \& Relyea, 1993).

Our findings were consistent with those of others (e.g., Weekley et al., 1992), 
Table 1. Comparisons Between Female Weight-Control Smokers (WC) and Non-Weight-Control Smokers (NWC) (means $\pm S D$ )

\begin{tabular}{|c|c|c|c|}
\hline & $\begin{array}{c}\text { WC } \\
(n=46)\end{array}$ & $\begin{array}{c}\text { NWC } \\
(n=52)\end{array}$ & Significance \\
\hline \multicolumn{4}{|l|}{ Demographics } \\
\hline Age (years) & $33.3 \pm 8.0$ & $32.9 \pm 9.7$ & n.s. \\
\hline Height (in.) & $64.3 \pm 2.9$ & $65.5 \pm 2.8$ & $p=.047$ \\
\hline Weight (lb) & $139.4 \pm 24.4$ & $146.7 \pm 42.4$ & n.s. \\
\hline Body Mass Index $\left(\mathrm{kg} / \mathrm{M}^{2}\right)$ & $23.7 \pm 3.9$ & $24.0 \pm 6.5$ & n.s. \\
\hline \% Smoking-Cessation Patients & 47.8 & 40.4 & n.s. \\
\hline$\%$ White & 96.4 & 90.0 & n.s. \\
\hline Education & & & n.s. \\
\hline$\% 10-12$ years & 39.1 & 32.7 & \\
\hline$\% 13-15$ years & 32.6 & 40.4 & \\
\hline$\geq 16$ years & 28.3 & 26.9 & \\
\hline$\%$ Married & 50.0 & 35.0 & n.s. \\
\hline \multicolumn{4}{|l|}{ Smoking-Related Variables } \\
\hline Intake (Cigarettes/Day) & $-24.5 \pm 6.2$ & $23.1 \pm 8.3$ & n.s. \\
\hline FTQ (Scale 0-11) & $7.2 \pm 1.7$ & $6.8 \pm 1.8$ & n.s. \\
\hline Cotinine (ng/ml) & $243.2 \pm 92.3$ & $300.0 \pm 126.4$ & $p=.064$ \\
\hline SMQ Nonpharmacological & & & n.s. \\
\hline Indulgent & $3.7 \pm 1.8$ & $3.5 \pm 1.7$ & n.s. \\
\hline Psychosocial & $4.0 \pm 2.3$ & $3.0 \pm 2.4$ & $p=.054$ \\
\hline Sensorimotor & $2.6 \pm 1.5$ & $2.0 \pm 1.5$ & $p=.060$ \\
\hline SMQ Pharmacological & & & $p=.009$ \\
\hline Stimulation & $5.1 \pm 2.0$ & $4.0 \pm 2.3$ & $p=.018$ \\
\hline Addictive & $6.7 \pm 1.9$ & $5.3 \pm 2.2$ & $p=.001$ \\
\hline Automatic & $2.3 \pm 2.6$ & $1.7 \pm 2.5$ & n.s. \\
\hline Sedation & $7.7 \pm 1.7$ & $6.7 \pm 1.8$ & $p=.008$ \\
\hline Favorite Cigarette at Mealtime? (\% yes) & 35.6 & 32.7 & n.s. \\
\hline No. Past Quit Attempts & $1.2 \pm 1.2$ & $2.5 \pm 1.8$ & n.s. \\
\hline Appetite Change & & & $p=.000$ \\
\hline \% Decrease or No Change & 7.6 & 60.5 & \\
\hline$\%$ Increase & 92.3 & 39.5 & \\
\hline Weight Change & & & $p=.000$ \\
\hline \% Decrease or No Change & 15.8 & 72.1 & \\
\hline$\%$ Increase & 84.2 & 27.9 & \\
\hline Increased Anxiety? (\% yes) & 77.3 & 56.0 & $p=.030$ \\
\hline Increased Anger? ( $\%$ yes) & 47.7 & 36.6 & n.s. \\
\hline Increased Fatigue? (\% yes) & 31.8 & 18.0 & n.s. \\
\hline Increased Depression? (\% yes) & 31.8 & 18.0 & n.s. \\
\hline Decreased Concentration? (\% yes) & 47.7 & 32.0 & n.s. \\
\hline \multicolumn{4}{|l|}{ Eating, Alcohol, Caffeine, and Exercise } \\
\hline \multicolumn{4}{|l|}{ TFEO } \\
\hline Cognitive Restraint & $11.7 \pm 5.8$ & $3.9 \pm 2.5$ & $p=.000$ \\
\hline Disinhibition & $7.9 \pm 3.2$ & $4.8 \pm 3.8$ & $p=.038$ \\
\hline Hunger & $5.3 \pm 3.5$ & $5.2 \pm 3.5$ & n.s. \\
\hline
\end{tabular}


Table 1. (Continued)

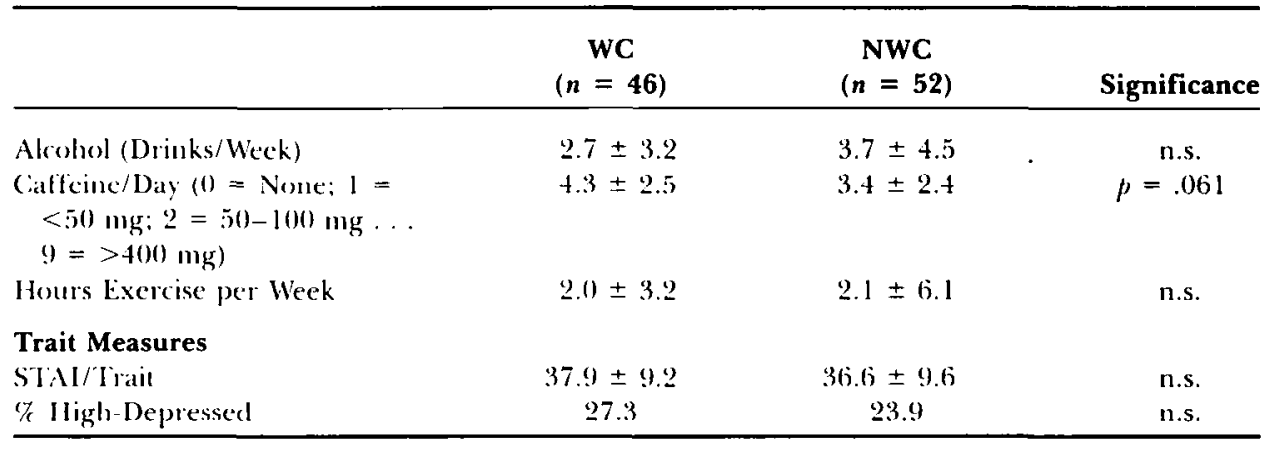

Nolt. Tests used to detect significant differences are described in the text. FTQ $=$ Fagerstrom Tolerance Questionnaire, $\mathrm{SMQ}=$ Smoking Motiation Questionnaire, TFEQ = Three-Factor Eating Questionnaire, STAI = State-Irait Anxiety Invemory.

in that we found that WC were not more nicotine dependent than were NWC using standard measures, and possibly less dependent, using a trend toward lower cotinine values as an index. Elevated scores on the SMQ pharmacological "metamotive," however, suggests a greater tendency on the part of WC to use nicotine to promote interoceptive state changes, and perhaps greater sensitivity to nicotine's ability to cause such state changes. WC were consistently more likely than NWC to report having experienced increases in negative affect during previous quit attempts, although, except for anxiety, the differences failed to reach significance. Such self-reports, however, are obviously subject to recall bias, and they are not substantiated by significant correlations between WCSS scores and withdrawal symptomatology over 48 hours' abstinence in Study 2. One other finding of interest was the marginal excess in caffeine intake in WC, which might reflect a general tendency to prefer and/or respond to stimulants.

Virtually all other important differences between WC and NWC were related to the attitudes of the former toward eating and to their perception, based on their own past experiences, that nicotine abstinence promoted weight gain and increased hunger. Moreover, these findings receive support from Study 2, in that WCSS scores were significantly correlated with the emergence of increased eating over the 48-hour abstinence period. Increased hunger did not prove to be significantly correlated with higher WCSS scores in this small sample, possibly because under conditions of increased eating, actual hunger was somewhat prevented from emerging; had we used the term "increased appetite," we might have elicited a different response.

The correlation of cotinine levels with body weight in NWC was not surprising, because nicotine intake suppresses body weight in a dose-related fashion (e.g., Grunberg, Bowen, Maycock, \& Nespor, 1985). The failure to find a similar correlation in WC may be an artifact of the relatively lower variability in weight seen in that group. An alternative possibility, however, is that the WC were doing something in addition to smoking to control their weight. If so, that something clearly was not exercise, because hours of weekly exercise were almost identical 
in the two groups. More likely, the markedly higher scores of WC on the Cognitive Restraint subscale of the TFEQ, compared with those of NWC (which replicate recent findings of Camp et al., 1993, and of Weekley ct al., 1992), reflect habitual efforts at dietary restraint. Similar findings for the Disinhibition subscale (Study 1), combined with the observed link between WCSS scores and increased eating during the first 48 hours of withdrawal (Study 2), suggest that nicotine withdrawal may precipitate episodes of disinhibited or binge-eating in such women. And because high Disinhibition scores have been found to predict weight gain among abstinent smokers (Hall, Ginsberg, \& Jones, 1986), such women may be expected to include an excess of "supergainers."

We infer from our data that many WC are vulnerable to patterns of excess or unpredictable eating and consequently to substantial weight gain that can be managed by nicotine. If our inference is substantiated by prospective, experimental research, then it is likely that improvements both in recruitment to treatment and in sustained success at abstinence in those women who are most sensitive to nicotine's anorectic effects and/or most concerned about loss of such effects will depend on the development of appropriate and highly focused strategies. The failure of one innovative and intensive program combining weight control and smoking cessation instruction (Hall, Tunstall, Vila, \& Duffy, 1992) to improve on smoking cessation rates in comparison to standard treatment methods suggests that devising the most effective formula will not be easy. Possible strategies might include: (a) Specific targeting of WC-for example, in treatment groups of women selected for high WCSS scores-might permit more attention to be given to their needs than is possible or desirable in less focused groups. (b) The findings of Bowen, Spring, and Fox (1991) that subjects placed on high-carbohydrate, low-protein diets and tryptophan supplements postcessation were more likely to remain abstinent compared with controls receiving standard smoking-cessation treatment suggest a likely explanation for the puzzling and seemingly paradoxical observation that weight gain during cessation predicts continued subsequent abstinence (Gritz, Berman, Read, Marcus, \& Siau, 1990; Hall et al., 1986; Norregaard, Tonnesen, \& Peterson, 1993): Quitters who substitute preferred (high-calorie) foods as a reinforcer (Leischow \& Stitzer, 1991) are more likely to be successful. For WC, however, such substitution may be more problematical than for smokers less susceptible to overeating/weight gain following cessation. The use of nonnicotine agents known to prevent postcessation weight gain (e.g., fluoxetine; Pomerleau, Pomerleau, Morrell, \& Lowenbergh, 1991; Spring, Wurtman, Gleason, Wurtman, \& Kessler, 1991; or phenylpropanolamine; Klesges, Klesges, Meyers, Kelm, \& Isbell, 1990), alone or in the context of nicotine-replacement tapering, may be particularly useful in helping WC to remain abstinent without resorting to excessive eating. Although acquisition of new eating and exercise habits would still be required eventually, it could be deferred until after abstinence from nicotine (via cigarettes or transdermally) had been well established. (c) Behavioral techniques shown to be effective for dealing with disinhibited or binge eating, such as cue exposure, may be useful for WC during nicotine withdrawal. 
Although smoking rates have been declining, the contribution of men to this trend is greater than that of women, and there are few grounds for a complacent belief that the downturn in smoking among women could not be reversed. Because weight-control considerations motivate a surprisingly large proportion of female smokers, a better understanding of the nature and needs. of this population could make a substantial impact upon the women's public health problem that smoking represents. For this reason, we believe that our findings, and our interpretation of them, merit further investigation.

\section{REFERENCES}

American Psychiatric Association (1987). Diagnostic and statistical manual of mental disorders (3rd ed., rev.). Washington, DC: Author.

Beck, A.T., Ward, C.H., Mendelson, M., Mock, J., \& Erbaugh, J. (1961). An inventory for measuring depression. Archives of General Psychiatry, 4, 53-63.

Bowen, D.J., Spring, B.J., \& Fox. E. (1991). Tryptophan and high carbohydrate diet as adjuncts to smoking cessation therapy. Jounal of Beluavioral Medicine, 41, 97-110.

Brandon, T.H., \& Baker, T.B. (1991). The Smoking Consequences Questionnaire: The subjective expected utility of smoking in college students. Psychological Assessment, 3, 484-491.

Camp, D.E., Klesges, R.C., \& Relyea, C. (1993). The relationship between body weight concerns and adolescent smoking. Health Psychology, 12, 24-32.

Fagerstrom, K. (1978). Measuring degree of physical dependence to tobacco smoking with reference to individualization of treatment. Addictive Behaviors, 6, 345-353.

French, S.A., Jeffrey, R.W., Pirie, P.L., \& McBridge, C.M. (1992). Do weight concerns hinder smoking cessation efforts? Addictive Behaviors, 17, 219-226.

Gritz, E.R., Berman, B.A., Read, L.L., Marcus, A.C., \& Siau, J. (1990). Weight change among registered nurses in a self-help smoking cessation program. American Journal of Health Promotion, 5, 115-121.

Gritz, E.R., Ippoliti, A., Jarvik, M.E., Rose, J.E., Shiffman, S., Harrison, A., \& Van Vunakis, H. (1988). The effect of nicotine on the delay of gastric emptying. Alimentary Pharmacology Therapeutics, 2, 173-178.

Grunberg, N.E. (1982). The effect of nicotine and cigarette smoking on food consumption and taste preferences. Addictive Behavior. 7, 317-331.

Grunberg, N.E., Bowen, D.J., Maycock, V.A., \& Nespor, S.M. (1985). The importance of sweet taste and caloric content in the effects of nicotine on specific food consumption. Psychopharmacology, Biochemistry, and Behavior, 23, 851-854.

Hall, S.M., Ginsberg, D., \& Jones, R.T. (1986). Smoking cessation and weight gain. Joumal of Consulting and Clinical Psychology, 54, 342-346.

Hall, S.M., McGee, R., Tunstall, C., Duffy, J., \& Benowitz, N. (1989). Changes in food intake and activity after quitting smoking. Journal of Consulting and Clinical Psychology, 57, 81-86.

Hall, S.M., Tunstall, C., Vila, K., \& Duffy, J. (1992). Weight gain prevention after smoking cessation: Cautionary findings. American Journal of Public Health, 82, 799-803.

Hariharan, M., VanNoord, T., \& Greden, J.F. (1988). A high-performance liquid-chromatographic method for routine simultaneous determination of nicotine and cotinine in plasma. Clinical Chemistry, 34, 724-729.

Jacob, P., Wilson, M., \& Benowitz, N.L. (1981). Improved gas chromatographic method for the determination of nicotine and cotinine and other biologic fluids. Journal of Chromatography, $222,61-70$.

Klesges, R.C., Klesges, L.M., Meyers, A.W., Klem, M.L., \& Isbell, T. (1990). The effects of phenylpropanolamine on dietary intake, physical activity, and body weight following smoking cessation. Clinical Pharmacology and Therapeutics, 47, 747-754. 
Klesges, R.C., \& Shumaker, S.A. (1992). Understanding the relations between smoking and body weight and their importance to smoking cessation and relapse. Health Psychology, 11 (Suppl.), 1-3.

Leischow, S.J., \& Stitzer, M.L. (1991). Smoking cessation and weight gain. British Journal of Addiction, $86,577-581$.

Moffatt, R.J., \& Owens, S.G. (1991). Cessation from cigarette smoking: Changes in body weight, body composition, resting metabolism and energy consumption. Metabolism, 40, 465-475.

Norregaard, J., Tonnesen, P., \& Petersen, L. (1993). Predictors and reasons for relapse in smoking cessation with nicotine and placebo patches. Preventive Medicine, 22, 261-271.

Pomerleau, O.F., Pomerleau, C.S., Morrell, E.M., \& Lowenbergh, J.L. (1991). Effects of fluoxetine upon weight gain and food intake in smokers who reduce nicotine intake. Psychoneuroendocrinology, 16, 433-440.

Russell, M.A.H., Peto, J., \& Patel, U.A. (1973). The classification of smoking by factorial structure of motives. Journal of the Royal Statistical Society, 137, 313-333.

Schwartz, D.M., Thompson, M.G., \& Johnson, C.L. (1982). Anorexia nervosa and bulimia: The socio-cultural context. International Journal of Eating Disorders, 3, 20-36.

Spielberger, C.D., Gorsuch, R.L., Lushene, R., Vagg, P.R., \& Jacobs, G. A. (1983). Manual for the State Trait Anxiety Inventory. Palo Alto, CA: Consulting Psychologists Press.

Spring, B.J., Wurtman, J., Gleason, R., Wurtman, R., \& Kessler, K. (1991). Weight gain and withdrawal symptoms after smoking cessation: A preventive intervention using d-fenfluramine. Health Psychology, 10, 216-223.

Stunkard, A.J., \& Messick, S. (1985). The Three-Factor Eating Questionnaire to measure dietary restraint, disinhibition and hunger. Journal of Psychosomatic Research, 29, 71-83.

Tate, J.C., Pomerleau, C.S., \& Pomerleau, O.F. (in press-a). Pharmacological and nonpharmacological smoking motives: A replication and extension. (Addiction)

Tate, J.C., Pomerleau, O.F., \& Pomerleau, C.S. (1993). Stability and within-subject consistency of nicotine withdrawal symptoms. Joumal of Substance Abuse, 5, 355-363.

Weekley, C.K., Klesges, R.C., \& Relyea, G. (1992). Smoking as a weight-control strategy and its relationship to smoking status. Addictive Behaviors, 17, 259-271.

Weissman, M.M., Scholomakis, D., Pottenger, M., Prushoff, B.A., \& Locke, B.Z. (1977). Assessing depressive symptoms in five psychiatric populations: A validation study. American Journal of Epidemiology, 106, 203-214.

Williamson, D.F., Madans, J., Anda, R.F., Kleinman, J.C., Giovino, G.A., \& Byers, T. (1991). Smoking cessation and severity of weight gain in a national cohort. New England Journal of Medicine, 324 , 739-745. 